\title{
A Short Review on Electrochemical Sensing of Commercial Dyes in Real Samples Using Carbon Paste Electrodes
}

\author{
Isha Soni (D), Pankaj Kumar, Shruti Sharma and Gururaj Kudur Jayaprakash *D \\ School of Advanced Chemical Sciences, Shoolini University, Bajhol, Solan 173229, Himachal Pradesh, India; \\ ishasoni065@gmail.com (I.S.); pankajsharma12j@gmail.com (P.K.); lovika9sharma@gmail.com (S.S.) \\ * Correspondence: gururaj@shooliniuniversity.com
}

Citation: Soni, I.; Kumar, P.; Sharma,

S.; Kudur Jayaprakash, G. A Short Review on Electrochemical Sensing of Commercial Dyes in Real Samples Using Carbon Paste Electrodes.

Electrochem 2021, 2, 274-294.

https://doi.org/10.3390/

electrochem 2020020

Academic Editor: Masato Sone

Received: 25 April 2021

Accepted: 21 May 2021

Published: 25 May 2021

Publisher's Note: MDPI stays neutral with regard to jurisdictional claims in published maps and institutional affiliations.

Copyright: (C) 2021 by the authors. Licensee MDPI, Basel, Switzerland. This article is an open access article distributed under the terms and conditions of the Creative Commons Attribution (CC BY) license (https:// creativecommons.org/licenses/by/ $4.0 /)$.

\begin{abstract}
Synthetic dyes are commonly used in food products like soft drinks, vegetable sauces, jellies, etc. Most artificial dyes can cause cancer, therefore it is very important to develop sensors to detect them in food samples. Voltammetric methods with carbon paste electrodes (CPEs) are promising for this purpose. However, modification of CPEs is necessary to detect the commercial dyes in food samples in the presence of interferents. In the current review, we have discussed the different previous research in which detection of dyes is performed in real samples with good detection limits. The current review will be helpful for readers who are interested in developing low-cost electrodes for the effective determination of dyes in commercial products like soft drinks and vegetable sauces.
\end{abstract}

Keywords: voltammetry; dyes; sensors; electron transfer; carbon paste; modifications

\section{Introduction}

Dyes play an integral part in the present world. They are responsible for imparting colors due to chromophoric (azo, azoxy, nitro, carbonyl, thiocarbonyl) and auxochromic groups. They are different from pigments as the former are organic compounds and become attached chemically to the substrate while the latter do not form any chemical bonds and can be organic or inorganic compounds [1,2].

\subsection{Dye Classification}

Broadly, dyes can be classified into natural and synthetic based on the source of origin. Natural dyes can be extracted from natural sources such as fruits, flowers, leaves, roots, barks, etc., whereas synthetic dyes are synthesized in laboratories by the use of chemicals. In addition, they can be classified based on general structure into anionic, cationic, and nonionic, and categorized based on application characteristics into ten different types (acidic, basic, mordant, reactive, direct, disperse, sulfur dye, pigment, vat, azo insoluble) [2].

\subsection{Synthetic Dyes (Advantages and Disadvantages)}

Dyes influence every sphere of human life, be it food, leather, cosmetics, or the drug industry. By 1900, with an increase in demand, synthetic dyes gained immense attention and replaced natural dyes due to a variety of reasons such as low-cost production, easy availability, easy application, more color stability, resistance to light, $\mathrm{pH}$ changes, oxygen, etc. However, as every coin has two sides, dyes also have pros and cons. Therefore, considering their importance and large-scale industrial use, we cannot neglect their drawbacks. Some of these are described below [2].

I. They are not environmentally friendly as their synthesis involves extreme conditions such as high $\mathrm{pH}$, high temperature, strong acids, and heavy metal catalysts.

II. The most common substrate for dye production is petroleum, which is a nonrenewable source of energy. 
III. Synthesis generates a large amount of effluent which contains toxic chemicals generated as side products.

The increasing dependency of various industries on synthetic organic dyes, and their solubility in water, are a cause of great concern; due to inadequate environmental legislature, industrial effluent is discharged into water bodies without proper treatment. Although dyes constitute only a small proportion (less than or equal to $1 \mathrm{ppm}$ ) of the industrial effluent, they are quite stable and are resistant to light, various chemicals, and biological activities owing to their complex structure, remaining as such for a long period. Hence their accumulation causes an increase in biochemical oxygen demand (BOD), affecting the $\mathrm{pH}$ and chemical oxygen demand (COD) [3].

In addition, their increase affects the color of water bodies and affects absorption properties of planktonic life (decrease in photosynthetic activity). It is also seen that some of the dyes sequester metal ions and cause toxicity in marine animals [4].

These dyes also react with various other organic byproducts of the effluent, forming harmful aromatic complexes that result in mutations and cancers in aquatic animals. Recent studies have shown that dyes have genotoxic, cytotoxic, and mutagenic properties when exposed in greater concentrations to living organisms. They can also cause DNA fragmentations, allergies, skin irritations, and malfunctioning of various organs when acted upon by different biotic and abiotic factors due to the formation of toxic breakdown products $[5,6]$.

\subsection{Industrial Applications}

In the food industry [7,8], dyes act as color additives that impart appealing bright colors to the food products without giving any nutritional value. The first artificial food coloring was prepared from coal tar in 1856 and since then hundreds of dyes have been prepared, out of which only a few are permitted by food regulatory bodies (FDA, FSSAI, EEC) owing to health concerns. They have been reported as creating various health issues such as toxicity, cancers, allergies, hypersensitivities, etc., but still, research is ongoing to elucidate the harmful effects of food dyes on health.

The list of commonly used permitted dyes along with color imparted is given in Table 1.

Table 1. List of food permitted dyes along with wavelength and color they impart.

\begin{tabular}{ccc}
\hline Color & Wavelength $\AA$ & Dyes \\
\hline Red & $6400-7000$ & Carmoisine, Erythrosine, Allura Red \\
Yellow & $5500-5900$ & Tartrazine, Sunset Yellow \\
Blue & $4500-5100$ & Brilliant Blue, Indigo Carmine \\
Green & $5100-5500$ & Fast Green \\
\hline
\end{tabular}

In addition, some non-permitted dyes that are added to foodstuffs to enhance the color of the food are Fast Red, Mentanil Yellow, Bromocresol Purple, Green-S, and Sudan1-4. Hence the detection of these dyes is necessary.

Textile industry: It has been observed that $7 \times 10^{5}$ tons of synthetic dyes are produced every year around the globe, out of which about $2 \times 10^{5}$ tons are lost after various processing processes as waste effluent into water bodies. This waste effluent disturbs various water parameters such as $\mathrm{pH}$, salinity, $\mathrm{COD}, \mathrm{BOD}$, etc., as most of the dyes contain aromatic rings causing toxicity and mutagenicity, ultimately affecting aquatic life adversely [9-11].

The two important classes of dyes that are employed in the textile industry include azo and anthraquinone.

Azo dyes are characterized by the presence of $-\mathrm{N}=\mathrm{N}$ - bonds mainly imparting yellow, orange, and red colors. Anthraquinone is used for violet-blue or green colors.

Pharmaceutical industry: This industry [12] also employs various food dyes in processing pharmaceutical products such as tablets, capsules, syrups, etc. Dyes provide appealing 
appearance and easy identification for similar drugs. However, considering various ill effects of dyes, certain permissible amounts are fixed for using dyes. Dyes often used in the manufacturing process are tartrazine, quinoline, Sunset Yellow, amaranth, Allura Red, erythrosine, and Brilliant Blue.

On similar grounds, dyes are used in other industries for their color attracting properties and to appeal to the customers as per their requirements.

Dye degradation methods are categorized into three types: chemical, physical, and biological. The physical method includes adsorption (using activated carbon, silica, fly ash, bio adsorbent, polymeric adsorbent), irradiation, and filtration; the chemical methods include oxidation (using $\mathrm{UV}, \mathrm{H}_{2} \mathrm{O}_{2}, \mathrm{O}_{3}$ ), coagulation, and precipitation; while biological methods include aerobic and anaerobic methods [6,13].

\subsection{Methods for Dye Detection}

Various chemical methods have been reported for the detection of dyes, such as chromatography (HPLC, TLC, RPLC), capillary electrophoresis, mass spectrometry, spectrophotometry, immunoassay techniques (ELISA), etc. Among these the most employed technique is HPLC. However, these techniques are time-consuming and are expensive using highly skilled labor. Moreover, capillary electrophoresis, ELISA, and mass spectrometry do not work on neutral molecules and require charged molecules to work $[14,15]$.

Besides the above-mentioned techniques, electrochemical methods, especially voltammetric techniques such as cyclic voltammetry (CV), differential pulse voltammetry (DPV), square-wave voltammetry (SWV), polarography, etc., have gained immense attention. The voltammetric studies employ the use of a three-electrode system: working electrode, counter electrode (non-reactive), and a reference electrode (helps to monitor the potential of the working electrode). The working electrodes can be solid (mainly graphite, carbon, diamond, bismuth, platinum, and gold) or liquid (mercury) and can be easily modified using organic and inorganic ions, molecules, polymers, or nanoparticles (NPs) for enhancing the electron transport rate [16].

Compared with other detection methods, voltammetric methods offer many advantages [17]:

(i) they decrease the capacitive current;

(ii) they are best for organic and inorganic molecules, which are electroactive;

(iii) they give lower detection limits as the preconcentration of the analyte is prevented;

(iv) an easily renewable surface of the working electrodes is possible;

(v) lightweight and small instruments are employed;

(vi) they not only determine the concentration but also give the composition of different species;

(vii) they can also be applied to solid analytes.

Apart from the above-mentioned properties, they are fast, cost-effective, user-friendly, and show high specificity and sensitivity with low-quantity sample usage $[18,19]$.

The current article describes the electrochemical methods for the detection of the following dyes using carbon paste electrodes as working electrodes.

\section{Voltammetric Detection of Dyes}

\subsection{Detection of Sunset Yellow (SY)}

Sunset Yellow is a synthetic azo dye (Figure 1) imparting a yellow to orange-yellow color. It is a permitted color additive and is widely employed in the food industry. It is commonly found as a disodium salt but can also be employed as potassium and calcium salts. The maximum permissible limit is $20 \mathrm{mg} / \mathrm{kg}$ in various food products. 


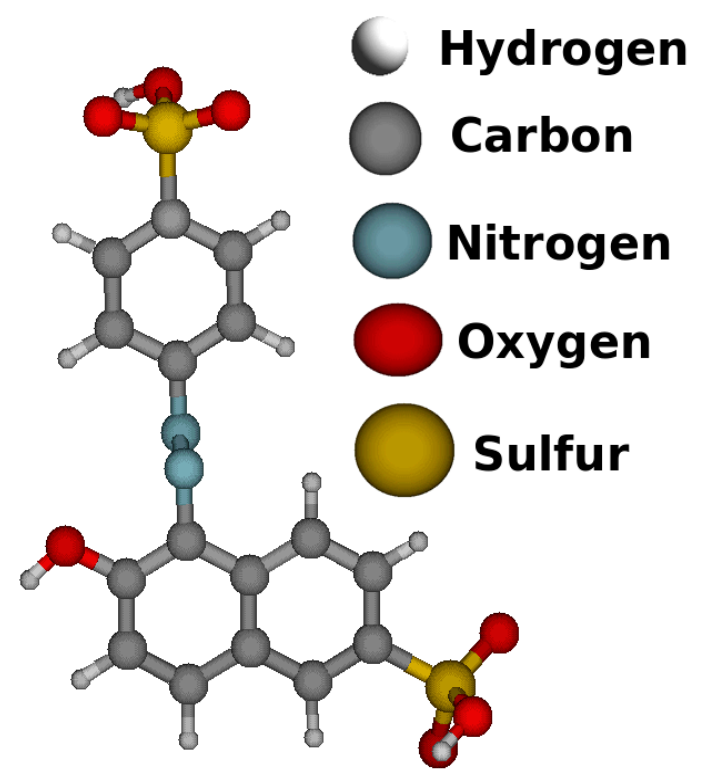

Figure 1. Ball and stick atomic model of Sunset Yellow.

X. Chen et al. [20] detected SY in alumina-nanofiber-modified CPE in 2013 using DPV and CV studies. DPV of modified CPE showed an 8-fold increase in oxidation peak current as compared to bare CPE while the results for CV are shown in Figure 2. Thus, alumina nanofibers helped in detection precision with no influence of interfering molecules $(<5 \%)$. Aluminum-nanofiber-modified CPE was applied to detect SY in soft drink samples and the obtained results were good with $<4.5 \%$ deviation. The detection limit of the aluminananofiber-modified electrodes was $0.16 \mathrm{nM}$. The detection of SY was also performed for montmorillonitecalcium (MMT-Ca) functionalized cetyltrimethylammonium bromide (CTAB)-modified CPE by Y. Songyang et al. [21] in 2014. The oxidation behavior was studied for MMT-Ca/CPE and CTAB/MMT-Ca/CPE using CV. After the modifications, reversibility and peak currents were increased which was due to cationic exchange between CTAB and MMT-Ca and an increase in accumulation of dye at the electrode surface. Modified electrodes showed good sensitivity towards SY with a detection limit of $0.71 \mathrm{nM}$. In 2015, D. Sun et al. [22] modified the CPE by resorcinol-formaldehyde polymer films for the detection of SY using DPV in a phosphate buffer solution (PBS). After the modification, electrode sensitivity was improved and redox electron transfer reactions were fast because of the increased surface area and strong adherence of the resorcinol formaldehyde film at the modified electrode interface. They also performed real sample analysis using wastewater and soft drinks. Their results were good with a detection limit of $0.09 \mathrm{nM}$. In 2016 Z. Wang et al. [23] modified the CPE from molecularly imprinted polymers (MIPs) for determining SY. The sensitivity of the molecular imprinted polymer-modified electrodes was further improved by the addition of multi-walled carbon nanotubes (MWCNTs). Their results proved that a combination of multiwall carbon nanotubes and molecular-imprinted polymers increase the active surface area and conductivity at the modified CPE interface. Therefore, redox reactions of SY are easier and its effective detection is possible in the presence of metals like $\mathrm{Ca}^{2+}, \mathrm{Cu}^{2+}, \mathrm{Cl}^{-}$, and $\mathrm{NO}^{3-}$. In 2017, Y. Ya et al. [24] detected SY in a ZnONano flower modified CPE. The electron transfer mechanism of SY is shown in Figure 3. The modified electrode had strong adsorption ability and a large surface area, which were attributed to the excellent electro-catalytic activity of the electrode (shown in Figure 4). Detection of SY was possible in the presence of various interfering molecules such as inorganic ions, organic molecules, citric acid, vitamin C, dyes (Sudan Red, Allura Red, Tartrazine) with a detection limit of $0.10 \mu \mathrm{g} / \mathrm{L}$. Table 2 shows the detection limit of Sunset Yellow at the different modified carbon paste electrodes. 


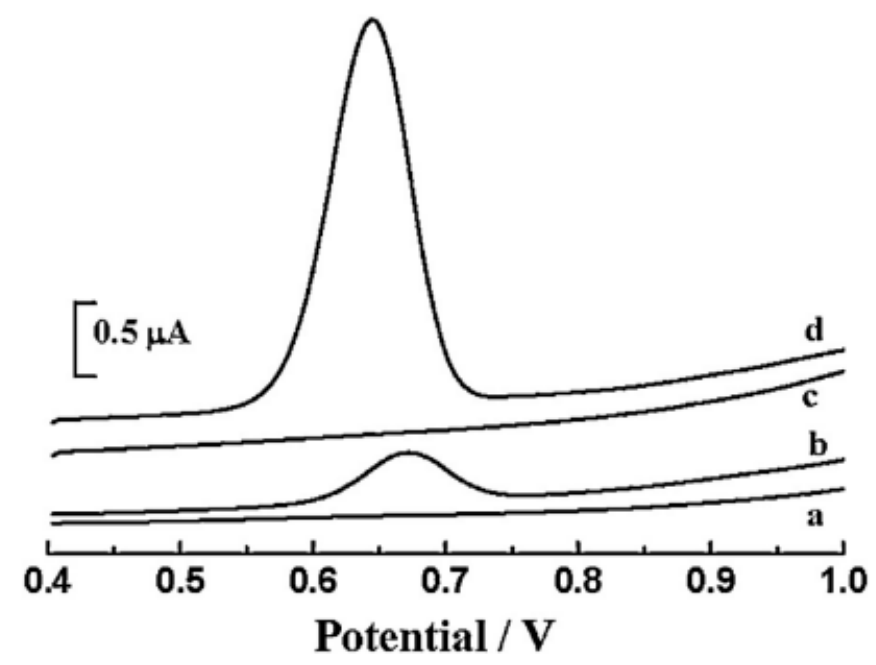

Figure 2. DPV curves of CPE (a and b) and alumina-microfiber-modified CPE (c and d) in pH 6.5 phosphate buffer ( $a$ and c) and in the presence of $100 \mathrm{nM}$ Sunset Yellow (b and d). Accumulation was performed at $0.4 \mathrm{~V}$ for $2 \mathrm{~min}$. Pulse amplitude: $50 \mathrm{mV}$, pulse width: $40 \mathrm{~ms}$, scan rate: $40 \mathrm{mV} \mathrm{s}^{-1}$. Reprinted with the permission of Reference [20]. [License Number 5067491296846].

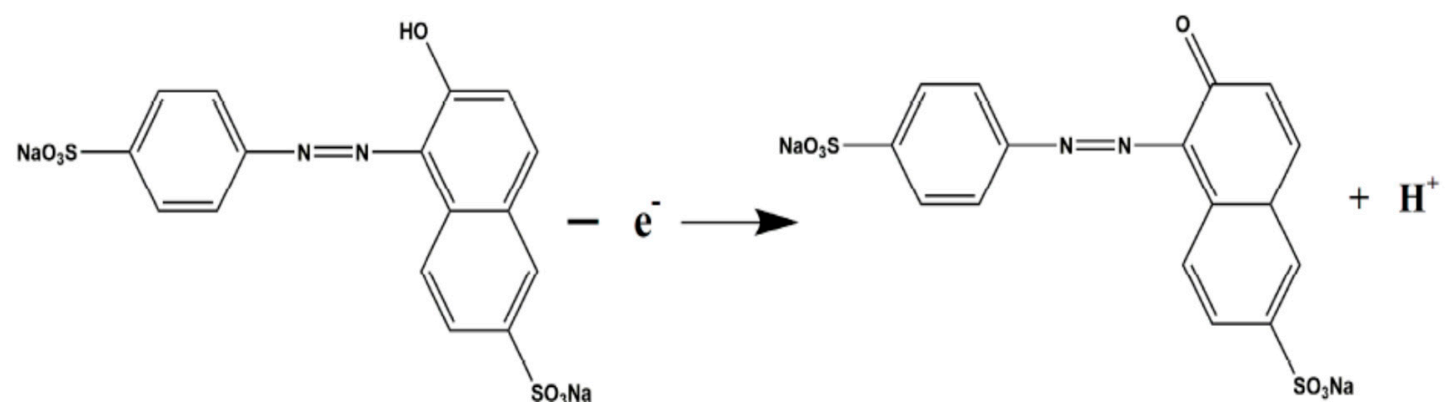

Figure 3. The electrochemical oxidation of Sunset Yellow. Reprinted with the permission of Reference [24].

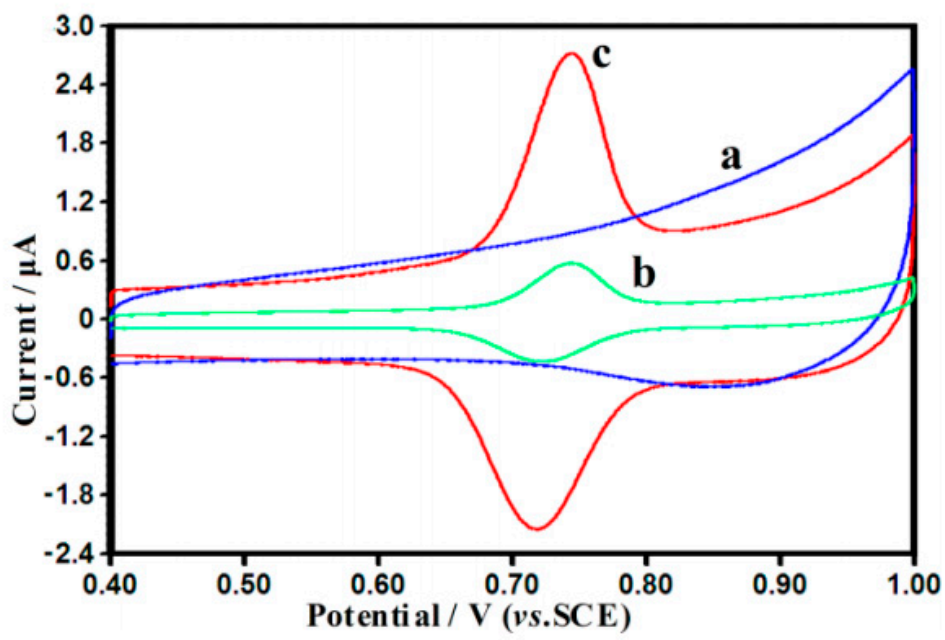

Figure 4. Cyclic voltammograms of (a) the ZnONF/CPE in pH 5.0 phosphate buffer solution (PBS) without SY; (b) the $40 \mu \mathrm{g} / \mathrm{L} \mathrm{SY}$ in pH 5.0 PBS at the bare CPE, and (c) the ZnONF/CPE. Reprinted with the permission of Reference [24]. 
Table 2. Table showing Sunset Yellow detection using carbon paste electrodes with different modifiers along with their detection limits.

\begin{tabular}{cccccc}
\hline S.No. & Modifier & Working Electrode & Detection Limit & Real Sample Used & Reference \\
\hline 1. & Alumina nanofibers & CPE & $0.16 \mathrm{nM}$ & Soft drink samples & [20] \\
\hline 2. & MMT-Ca & CPE & $0.71 \mathrm{nM}$ & Different drink samples & [21] \\
\hline 3. & Resorcinol-formaldehyde resin & $\mathrm{CPE}$ & $0.09 \mathrm{nM}$ & $\begin{array}{c}\text { Wastewater and drink } \\
\text { samples }\end{array}$ \\
\hline 4. & MWCNT/MIP & $\mathrm{CPE}$ & $26.67 \mathrm{nM}$ & Soft drink samples \\
\hline 5. & ZnONano flower & $\mathrm{CPE}$ & $0.10 \mu \mathrm{g} / \mathrm{L}$ & Soft drink samples & [23] \\
\hline
\end{tabular}

\subsection{Detection of Tartrazine (TR)}

Tartrazine (Figure 5) is a synthetic azo, water-soluble food dye. It imparts a yellow or greenish-yellow color. It is widely used in the food, pharmaceutical, and cosmetic industries. The maximum permissible limit is $7.5 \mathrm{mg} / \mathrm{kg} /$ day of body weight. This dye is also reported to be neurotoxic, genotoxic, and even causes allergic responses.

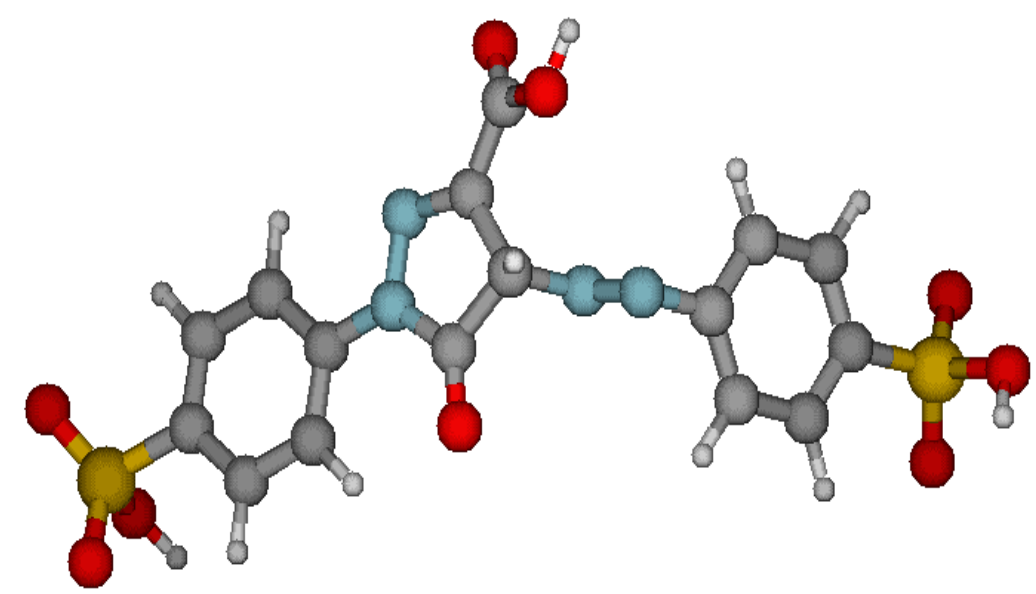

Figure 5. Ball and stick atomic model of Tartrazine.

S. M. Ghoreishi et al. [25] also detected TR in presence of Red 10B at Nano-Au modified CPE in 2013. The CV studies indicated that both the dyes show irreversible cyclic voltammetric behavior as displayed in Figure 6. This type of modified electrode gave a good sensitivity for detection of TR in the presence of Red 10B. Therefore, the modified electrode showed great conductivity and sensitivity with a detection limit of $0.017 \mu \mathrm{M}$. In 2016, K. Nezhad et al. [26] detected TR electrochemically at poly (p-amino benzene sulfonic acid) / poly (BSA) and ZnO NP modified CPE. The CV showed an irreversible oxidation peak with enhanced peak current due to increased conductivity and faster electron transfer rate; inorganic and organic molecules/ions do not affect the detection of TR at the modified electrode. The electrode gave a detection limit of $80 \mathrm{nM}$ and with real sample analysis using processed foodstuffs gave a recovery rate of $98 \%$ indicating good accuracy and precision of the electrode. In 2018, C. Raril et al. [27] also detected TR at surfactant (TX-100)-modified $\mathrm{CPE}$. The CV studies showed enhanced oxidation peak current at the modified electrode due to the presence of electro-active functional groups at the surface of the electrode, thus oxidation is adsorption controlled. This modified electrode gave a detection limit of $1.114 \mu \mathrm{M}$. In the same year, J. G. Manjunatha [28] detected TR at a CPE modified using poly(glycine). This modified electrode enhanced the electron transfer rate, due to which CV showed a well-defined peak at $910 \mathrm{mV}$ and gave a detection limit of $0.283 \mu \mathrm{M}$. The real sample analysis using food samples showed great recovery rates (94.5-98.2\%). In 2020, C. Raril et al. [29] used a surfactant, SDDS (sodium dodecyl sulfate)-modified CPE, for the de- 
tection of TR. They carried out CV and DPV studies and noticed a well-defined peak. This modified electrode gave a detection limit of $5.2 \mu \mathrm{M}$ with great sensitivity $(0.048 \mu \mathrm{A} / \mu \mathrm{M})$ and stability. Analysis of this modified electrode in various food samples gave a recovery ranging from $97.1 \%$ to $104 \%$. Table 3 shows the detection limits of Tartrazine at the different modified carbon paste electrodes.

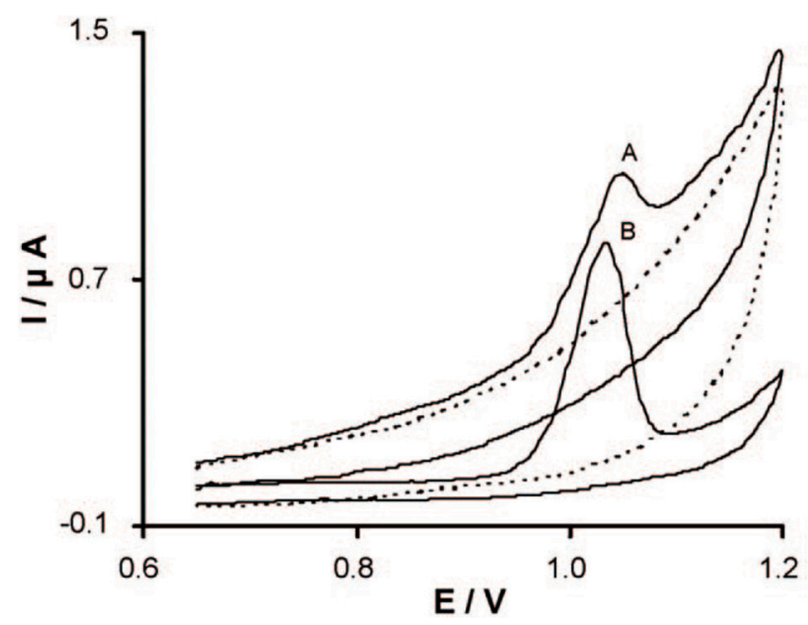

Figure 6. CVs of $1.5 \mu \mathrm{mol} \mathrm{L}{ }^{-1}$ Tartrazine in $\mathrm{pH} 4.0$ phosphate buffer at CPE (curve A), nano Au$\mathrm{CPE}$ (curve B), and nano Au-CPE at pH 4.0 without Tartrazine (dash line), scan rate $=100 \mathrm{mVs}^{-1}$. Reprinted with the permission of Reference [25]. [License Number 5067491496844].

Table 3. Table showing Tartrazine detection using carbon paste electrodes with different modifiers along with their detection limits.

\begin{tabular}{cccccc}
\hline S.No. & Modifier & Working Electrode & Detection Limit & Real Sample Used & Reference \\
\hline 1. & Nano-Au & CPE & $0.017 \mu \mathrm{M}$ & Soft drink samples & {$[25]$} \\
\hline 2. & Poly (BSA)+ZnO NPs & CPE & $80 \mathrm{nM}$ & soft drink samples \& orange powder & {$[26]$} \\
\hline 3. & TX-100 & CPE & $1.114 \mu \mathrm{M}$ & Not analyzed & {$[27]$} \\
\hline 4. & Poly (Glycine) & CPE & $0.283 \mu \mathrm{M}$ & Candy \& soft drink & {$[28]$} \\
\hline 5. & SDDS & CPE & $5.2 \mu \mathrm{M}$ & Tiger lemon yellow powder & {$[29]$} \\
\hline
\end{tabular}

\subsection{Simultaneous Detection of $S Y$ and $T R$}

S. M. Ghoreishi et al. [30] used a modified CPE for the simultaneous detection of SY and TR using cyclic voltammetry (CV) and differential pulse voltammetry (DPV) (shown in Figure 7). For simultaneous detection of SY and TR, they used Au nanoparticles for the modification. Voltammetric experiments were conducted using $\mathrm{KCl}$ saturated $\mathrm{Ag} / \mathrm{AgCl}$ as a reference electrode and platinum wire as a counter-electrode along with a CPE working electrode. The cyclic voltammograms gave a well-defined redox peak and they were $\mathrm{pH}$-dependent at the modified $\mathrm{CPE}$. After modifications from the gold, the nanoparticle (NP) electrode showed improved sensitivity and later same the electrodes were successfully applied to detect the analyte in soft drink samples. These works confirm that Au nanoparticles at the electrode interface are beneficial in SY and TR sensing. In 2018, CPE was modified using $\mathrm{Nd}_{2} \mathrm{O}_{3}$ [31] for the simultaneous detection of TR and SY. After the modifications, anodic peak currents were enhanced for both the dyes when compared to the bare CPE. This indicated improved sensitivity as less energy was required for the oxidation of the dyes with higher conductivity due to an increase in surface area by $\mathrm{Nd}_{2} \mathrm{O}_{3}$. The real sample analysis was performed using spiked unflavored gelatins, which gave a detection limit of $0.02 \mu \mathrm{M}$ for TR and $0.09 \mu \mathrm{M}$ for SY. In $2019 \mathrm{SY}, \mathrm{TR}$, and AR were detected at a cobalt-complex-modified CPE using CV by J. Pinagos-Llanos et al. [32]. They modified the 
electrode using the cobalt complex. The modified CPE was stable and showed enhanced conductivity with reduced diffusion time. After the modifications, real sample analysis was performed using flavored gelatine powder and the electrode showed a detection limit of $0.9 \mu \mathrm{M}$ for SY and $0.3 \mu \mathrm{M}$ for TR. Table 4 shows the detection limit of Sunset Yellow and Tartrazine at the different modified carbon paste electrodes.

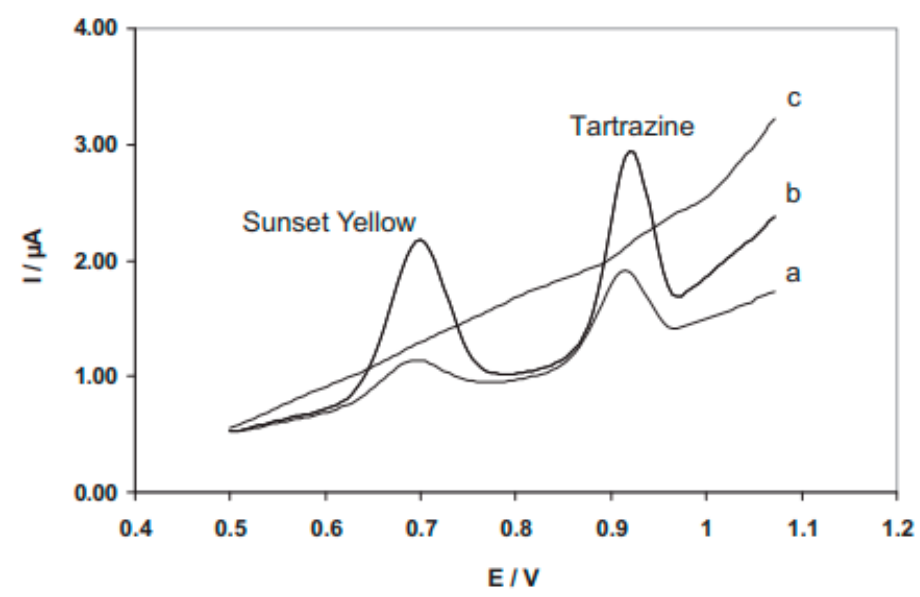

Figure 7. DPVs of $9.9 \times 10^{-7} \mathrm{~mol} \mathrm{~L}^{-1} \mathrm{SY}$ and $5.0 \times 10^{-7} \mathrm{~mol} \mathrm{~L}^{-1} \mathrm{TZ}$ at CPE (curve a) and nano Au-CPE (curve b). Curve (c): blank DPV of CPE. Accumulation time: $1 \mathrm{~min}$. Reprinted with the permission of Reference [30]. [License Number 5067500229498].

Table 4. Table showing Sunset Yellow and Tartrazine detection using carbon paste electrodes with different modifiers along with their detection limits.

\begin{tabular}{|c|c|c|c|c|c|c|}
\hline S.No. & Modifier & Dye & $\begin{array}{l}\text { Working } \\
\text { Electrode }\end{array}$ & $\begin{array}{l}\text { Detection } \\
\text { Limit }\end{array}$ & Real Sample Used & Reference \\
\hline 1. & $\mathrm{Au}$ NPs & $\begin{array}{l}\text { SY } \\
\text { TR }\end{array}$ & $\mathrm{CPE}$ & $\begin{array}{c}30 \mathrm{nM} \\
2 \mathrm{nM}\end{array}$ & Soft drink samples & {$[30]$} \\
\hline 2. & $\mathrm{Nd}_{2} \mathrm{O}_{3}$ & $\begin{array}{l}\text { SY } \\
\text { TR }\end{array}$ & $\mathrm{CPE}$ & $\begin{array}{l}0.09 \mu \mathrm{M} \\
0.02 \mu \mathrm{M}\end{array}$ & $\begin{array}{l}\text { Soft drink samples \& } \\
\text { orange powder }\end{array}$ & {$[31]$} \\
\hline 3. & Cobalt complex & $\begin{array}{l}\text { SY } \\
\text { TR }\end{array}$ & $\mathrm{CPE}$ & $\begin{array}{l}0.9 \mu \mathrm{M} \\
0.3 \mu \mathrm{M}\end{array}$ & $\begin{array}{c}\text { Flavored gelatine } \\
\text { powder }\end{array}$ & [32] \\
\hline
\end{tabular}

\subsection{Detection of Amaranth ( $A M)$}

Amaranth is a synthetic azo dye (Figure 8) capable of causing dizziness, nausea, and damage to various other important organs of the body. It is commonly employed in industries for its color-imparting applications. Hence, owing to health concerns, a permissible limit has been set up by various regulatory bodies for its uptake, i.e., $0.15 \mathrm{mg} / \mathrm{kg}$ of body weight per day. 


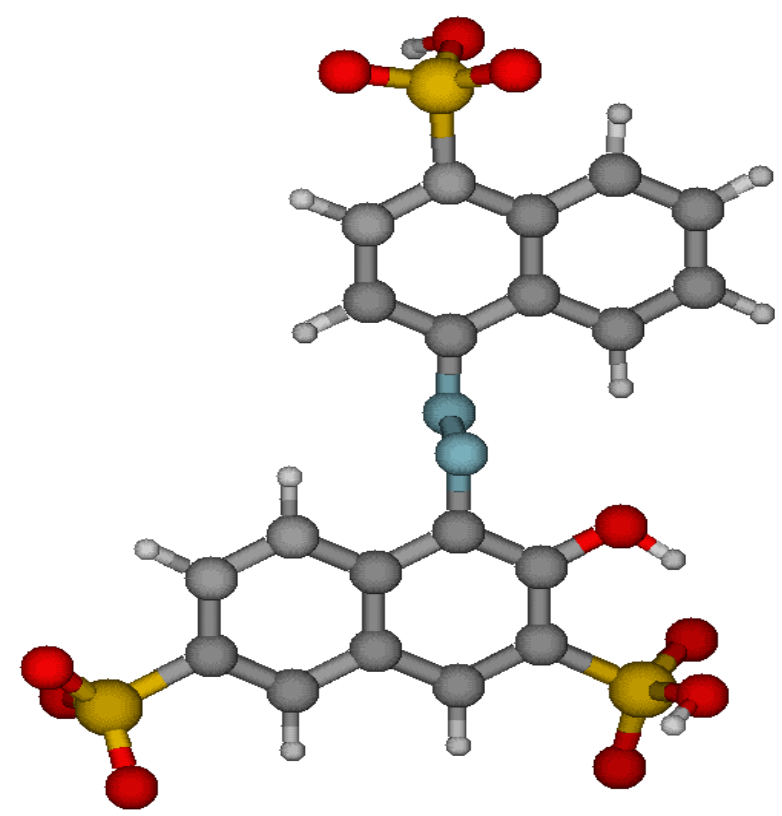

Figure 8. Ball and stick atomic model of Amaranth.

In 2008, M. Pandurangachar et al. [33] studied the adsorption behavior of AM at a surfactant (CTAB, Cetyl Trimethyl Ammonium Bromide)-modified CPE. It was seen using $\mathrm{CV}$ studies that the CTAB enhanced adsorption of AM at the surface of the modified electrode. At $<10 \mu \mathrm{L}$ concentration of the CTAB, dye formed monomers at the electrode surface while at $>40 \mu \mathrm{L}$ conc. of CTAB, monolayer formation was reported. Therefore, it was concluded that the surfactant enhanced the adsorption of dye at the surface of the electrode by increasing the surface area of the electrode and enhancing electroactive sites for dye interaction. M. L. Wang et al. [34] detected AM using square-wave adsorption stripping voltammetry (SWSV) on an expanded graphite paste electrode. SWSV showed a broad and well-defined anodic peak for AM at the modified electrode. This modified electrode gave a wide linear range with a detection limit of $0.005 \mu \mathrm{M}$. The real sample analysis was performed using soft drink samples giving a recovery $>96.5 \%$. These results were in consideration with those found using HPLC. In 2016, M.Sheikhshoaie et al. [35] detected $A M$ at a CPE modified using $\mathrm{RuO}_{2}$ Nano road (NR) and dipropylimidaizolium bromide (DPIR). CV studies showed irreversible oxidation of AM at the modified electrode with a maximum oxidation peak at PH 7 (shown in Figure 9). As compared to bare CPE, the electron transfer rate was enhanced at modified electrodes due to which excellent conductivity results were obtained. In addition, real sample analysis using food samples showed good results and in the presence of various interfering ions/molecules, the modified electrode was able to show great sensitivity. The modified electrode gave a detection limit of 3 nM. In 2017, M.Bijad et al. [36] detected AM with 1-Methyl-3-butylimidazolium bromide and a CuO-SWCNT-modified CPE in the presence of nitrite using SWV. The SWV showed two well-defined oxidation signals. The electrode gave a sensitivity of about $0.038 \mu \mathrm{A} / \mu \mathrm{M}$. Real sample analysis showed results less than the detection limit for in vitro studies (i.e., $0.001 \mu \mathrm{M}$ ). In 2020, AM was detected by S. Akbari [37] with graphene quantum dots/ionic liquid modified CPEs. There was an enhancement in peak current at the modified electrodes as shown by CV studies. Real sample analysis of AM using water samples from different sources in apple and orange juices showed good recovery rates $(>95 \%)$. The modified electrodes gave a detection limit of $30 \mathrm{nM}$ with a wide linear range. Table 5 shows the detection limits of Amaranth at the different modified carbon paste electrodes. 


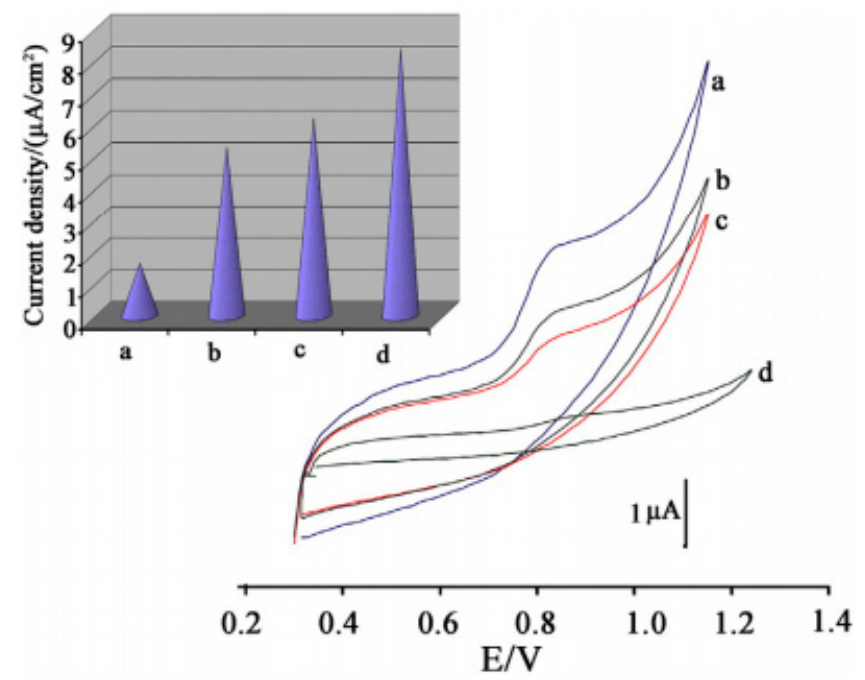

Figure 9. $\mathrm{CV}$ of (a) CPE/RuO2/NR/DPIBr; (b) CPE/DPIBr; (c) CPE/DPIBr; and (d) CPE in the buffer solution at $\mathrm{pH}=7.0$ in the presence of $200 \mu \mathrm{M}$ Amaranth. Inset: the current density derived from cyclic voltammogram responses of $200 \mu \mathrm{M}$ AM at pH 7.0 at the surface of different electrodes. Reprinted with the permission of Reference [35]. [License Number 5067500461346].

Table 5. Table showing Amaranth detection using carbon paste electrodes with different modifiers along with their detection limits.

\begin{tabular}{cccccc}
\hline S.No. & Modifier & Working Electrode & Detection Limit & Real Sample Used & Reference \\
\hline 1. & $\mathrm{CTAB}$ & $\mathrm{CPE}$ & Not detected & Not analyzed & [33] \\
\hline 2. & Graphite paste & $\mathrm{CPE}$ & $0.005 \mu \mathrm{M}$ & Wine samples & [34] \\
\hline 3. & $\mathrm{RuO}_{2} / \mathrm{DPIR}$ & $\mathrm{CPE}$ & $3 \mathrm{nM}$ & Soft drinks, apple and orange juices & [35] \\
\hline 4. & $\mathrm{Cu}_{2} \mathrm{O} / \mathrm{SWCNT}$ & $\mathrm{CPE}$ & $0.001 \mu \mathrm{M}$ & Sausages, apple and orange juices & [36] \\
\hline 5. & Graphene/IL & $\mathrm{CPE}$ & $30 \mathrm{nM}$ & $\begin{array}{c}\text { Tap water, well water, river water, } \\
\text { apple juice, and orange juice }\end{array}$ & [37] \\
\hline
\end{tabular}

\subsection{Detection of Allura Red (AR)}

Allura Red (Figure 10) is a water-soluble synthetic azo dye. The permissible daily intake value is $7 \mathrm{mg} / \mathrm{kg}$ body weight per day. It is widely employed in the food industry but is banned in some countries. It is dark red and is also soluble in $50 \%$ ethanol.

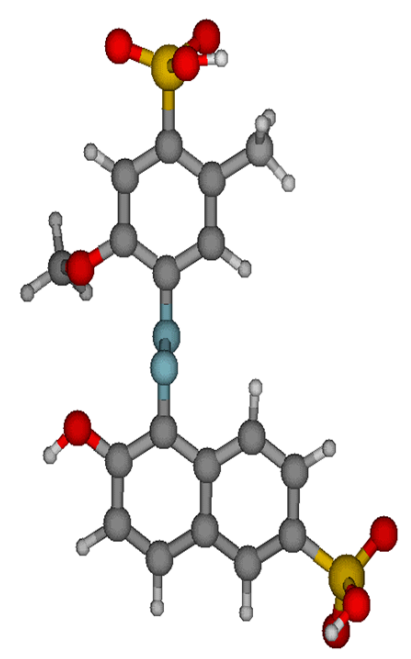

Figure 10. Ball and stick atomic model of Allura Red. 
In 2015, J. Zhang et al. [38] detected AR at an IL (ionic liquid) expanded graphite paste electrode (GPE/CPE) in the presence of Ponceau R dye. They conducted a CV and found enhancement in peak current at the modified electrode for both the dyes. The detection limit of $0.85 \mu \mathrm{g} / \mathrm{L}$ was found for AR with great sensitivity (with a deviation of $<4.76 \%$ ) in the presence of various interfering species. With real samples, the modified electrode gave a recovery ranging from $96 \%$ to $99.2 \%$. In 2019, J.-P. Llanos et al. [39] detected AR using cobalt-complex-modified $\mathrm{CPE}$. The $\mathrm{CV}$ showed the quasi-reversible process for the reduction of $\mathrm{AR}$ at the modified electrode with less energy requirement and faster electron transfer rate. The detection limit of $0.05 \mu \mathrm{M}$ was given at the modified electrode. With real sample analysis using soft and isotonic drinks, this modified electrode gave good recovery limits (>89\%). The detection of AR was performed using CPE modified using silica (SG) with cetylpyridinium chloride (CPC) by K. Pliuta et al. [40]. The optimal conditions were observed for SWV quantification: $\mathrm{PH}=2, \mathrm{E}_{\mathrm{ads}}=300 \mathrm{mV}$, tags $=300 \mathrm{~s}$, amplitude $-40 \mathrm{mV}$, frequency $-25 \mathrm{~Hz}$, and potential scan rate $250 \mathrm{mV} \mathrm{sec}{ }^{-1} .1 \times 10^{-2} \mathrm{M}$ of AR was dissolved in exact weight in double-distilled water for its preparation. The AR was determined in jelly sweets which were crushed and homogenized. A $1 \mathrm{~g}$ sample in $50 \mathrm{~mL}$ double-distilled water with heating was diluted up to $100 \mathrm{~mL}$ in the flask. Robinson buffer with $\mathrm{pH} 2$ was mixed properly with the aliquot. For the CV using a CPE/SG/CPC, the oxidation current increased, and the peak shifted to the cathode at $950 \mathrm{mv}$. This decrease in oxidation overvoltage was explained by Allura adsorption on the electrodes. For the ranges $0.04-0.2 \mu \mathrm{M}$ and $0.2-1.00 \mu \mathrm{M}$, the calibration plot had linearity. The values of a limit of quantification were $0.015 \mu \mathrm{M}$ and the limit of detection was $0.005 \mu \mathrm{M}$. In 2019, AR was simultaneously detected along with SY and TR [32] with a detection limit of $0.08 \mu \mathrm{M}$. Recently, R. Darabi et al. [41] detected SY, TR, and AR simultaneously at a $\mathrm{NiFe}_{2} \mathrm{O}_{4}$-reduced graphene/IL-modified CPE. This modified electrode was also successful in determining Allura Red dyes in real sample analysis in cosmetic and food products (deviation $<5 \%$ ). Table 6 shows the detection limits of Allura Red at the different modified carbon paste electrodes.

Table 6. Table showing Allura Red detection using carbon paste electrodes with different modifiers along with their detection limits.

\begin{tabular}{cccccc}
\hline S.No. & Modifier & Working Electrode & Detection Limit & Real Sample Used & Reference \\
\hline 1. & Cobalt decorated & $\mathrm{CPE}$ & $0.08 \mu \mathrm{M}$ & Flavored gelatine powder & [32] \\
\hline 2. & $\mathrm{IL}$ & $\mathrm{CPE}$ & $0.085 \mu \mathrm{g} / \mathrm{L}$ & Soft drink samples & [38] \\
\hline 3. & Cobalt composite & $\mathrm{CPE}$ & $0.05 \mu \mathrm{M}$ & Spiked unflavored gelatins & {$[39]$} \\
\hline 4. & $\mathrm{SG} / \mathrm{CPC}$ & $\mathrm{CPE}$ & $0.005 \mu \mathrm{M}$ & Jelly candies & {$[40]$} \\
\hline 5. & $\mathrm{NiFe}_{2} \mathrm{O}_{4} / \mathrm{rGO} / \mathrm{IL}$ & $\mathrm{CPE}$ & $0.03 \mu \mathrm{M}$ & Orange juice powder, hair shampoo & {$[41]$} \\
\hline
\end{tabular}

\subsection{Detection of Carmoisine (CR)}

Carmoisine (Figure 11) synthetic azo dye is widely used in the food industry, having two naphthalene units. It offers a color range from red to maroon with typical applications in food and beverages. It is used as a food colorant in sauces, candies, yogurt, and chewing gum, having permitted levels up to $5-50 \mathrm{mg} / 100 \mathrm{~g}$ or $/ 100 \mathrm{~mL}$ depending on the type of food. The average daily intake that is acceptable is $0-4 \mathrm{mg} / \mathrm{kg}$ body weight. 


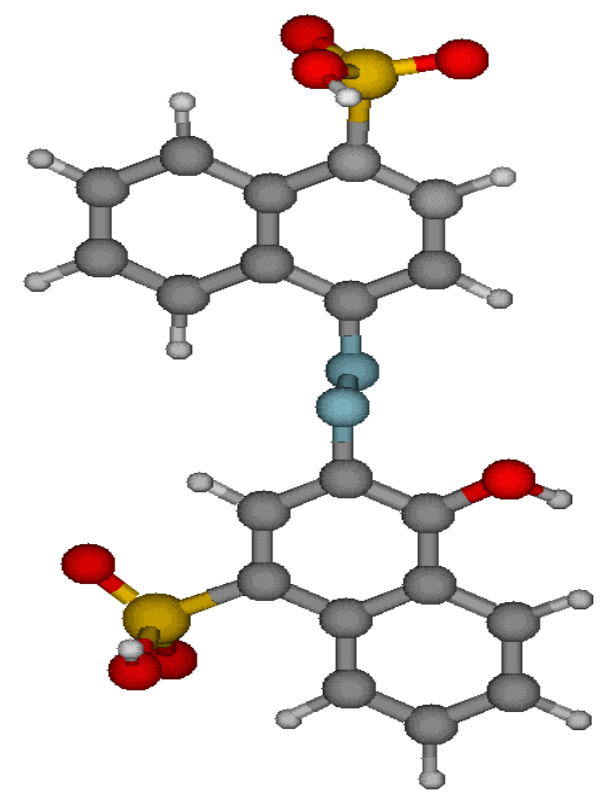

Figure 11. Ball and stick atomic model of Carmosine.

In 2017, M. Bijad et al. [42] detected CR at a CPE modified using NiO/CNT with 3-methyl-3-butyl imidazolium bromide (3BIBr) in the presence of TR. They used CV to compare the peak currents of bare and modified electrodes. Modified electrodes showed enhanced peak currents and the electron transfer process was irreversible. The electrode showed a detection limit of $20 \mathrm{nM}$ in the presence of TR. Dried fruit and soft drink samples were employed for the real sample analysis of both the dyes (TR and CR) and gave a recovery $>99.25 \%$. In 2018, H. M. Nehzad et al. [43] detected CR at a CPE modified using Cd/CNT\& 1-ethyl-3-methylimidazolium tetrafluoroborate (EMITB). They studied the electrochemical behavior of $C R$ at the modified electrode using linear sweep voltammetry (LSV) and found low oxidation current with enhanced peak current. This indicated good electrical conductivity and long-term stability of modified electrodes with a detection limit of $40 \mathrm{nM}$. The real sample analysis using fruit juices showed a recovery $>97 \%$ at this electrode. In 2020 the detection of CR was performed by using CPE modified by silica with cetylpyridinium chloride (CPE/SG/CPC), which has high sorption ability compared to azo dye (A. Chebotarev et al. [44]). The authors discussed the electrochemical behavior of $\mathrm{CR}$ on the CPE, CPE/SG, and CPE/SG/CPCl, in a detailed manner using SWV (shown in Figure 12) and $\mathrm{CV}$ at $\mathrm{pH}$ 2. The peak current is higher at $\mathrm{CPE} / \mathrm{SG} / \mathrm{CPCl}$ when compared to other electrodes. The limit of detection for this modified electrode was found to be $0.01 \mu \mathrm{M}$. Their results prove that silica with cetylpyridinium chloride will improve the $\mathrm{CR}$ adsorption on the electrode surface. Table 7 shows the detection limit of Carmoisine at the different modified carbon paste electrodes.

Table 7. Table showing Carmoisine detection using carbon paste electrodes with different modifiers along with their detection limits.

\begin{tabular}{cccccc}
\hline S.No. & Modifier & Working Electrode & Detection Limit & Real Sample Used & Reference \\
\hline 1. & $\mathrm{NiO} / \mathrm{CNT} / 3 \mathrm{BIBr}$ & $\mathrm{CPE}$ & $20 \mathrm{nM}$ & Dried fruit and soft drink samples & [42] \\
\hline 2. & $\mathrm{Cd} / \mathrm{CNT} / \mathrm{EMITB}$ & $\mathrm{CPE}$ & $40 \mathrm{nM}$ & Orange and lemon juices & [43] \\
\hline 3. & Silica & $\mathrm{CPE}$ & $0.01 \mu \mathrm{M}$ & Non-alcoholic soft drinks & {$[44]$} \\
\hline
\end{tabular}




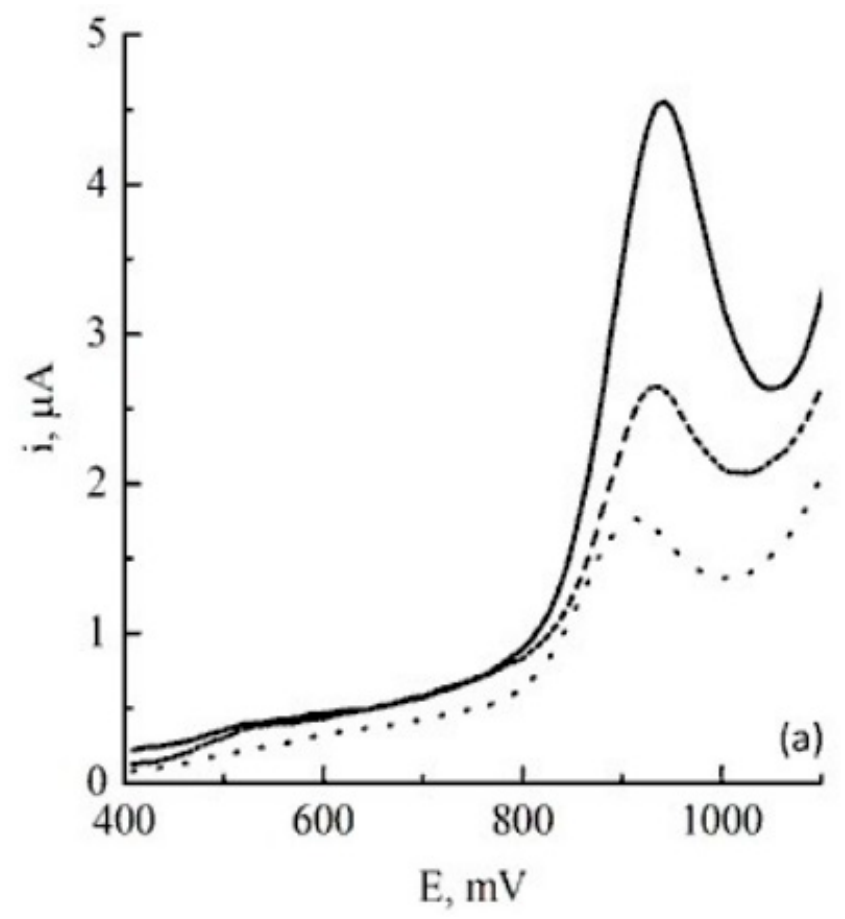

Figure 12. Square-wave voltammograms of Carmoisine solution on CPE (dash line), CPE/SG (dotted line). Reprinted with the permission of Reference [42]. [License Number 5070190415448].

\subsection{Detection of Rhodamine B (RHB)}

Rhodamine B (Figure 13) is also a non-permitted color additive due to its carcinogenic and acute poisoning properties. In addition, the dye can cause various environmental issues. It belongs to the xanthene class of dyes.

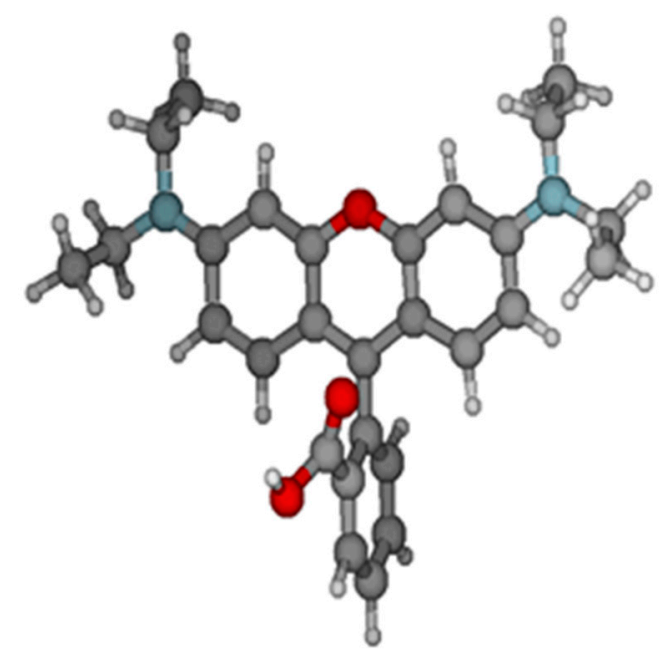

Figure 13. Ball and stick atomic model of Rhodamine B.

In 2019, Noviandri et al. [45] detected RHB at a CPE modified with molecularly imprinted poly (3aminophenol) (PAP) in the presence of TR. After the modification the electrode showed a good concentration linearity range with a detection limit of $1.17 \mathrm{pM}$. Real sample analysis was also performed using molecularly imprinted CPE and the obtained results were good (with $7.21 \%$ deviation). They further verified the results using UV spectroscopy methods. M. Golestaneh et al. [46] detected RHB at a CPE modified with MWCNT. They noticed a single cathodic peak with enhanced peak current using CV studies at the modified electrode. This modified electrode gave a detection limit of $20 \mathrm{nM}$ 
and a recovery ranging from $95-110 \%$ using real samples (hair color and water). Thus, MWCNT-modified electrode possesses electro-catalytic activity towards RHB with high stability and good repeatability (deviation of 3.9\%). In 2021, H. Setiyanto et al. [47] detected RHB at a CPE modified using MIP (polymer of glutamic acid) (PGA). Their potentiometric studies showed that the modified electrode was highly sensitive (sensitivity coefficient < $10^{-3}$ ) towards RHB with a detection limit of $8.91 \mu \mathrm{M}$. The results were in comparison to a $t$-test (0.12). Thus, modified electrodes show highly electrocatalytic behavior. Table 8 shows the detection limits of Rhodamine B at the different modified carbon paste electrodes.

Table 8. Table showing Rhodamine B detection using carbon paste electrodes with different modifiers along with their detection limits.

\begin{tabular}{cccccc}
\hline S.No. & Modifier & Working Electrode & Detection Limit & Real Sample Used & Reference \\
\hline 1. & MIP(PAP) & CPE & $1.17 \mathrm{pM}$ & Sekoteng and crackers & {$[45]$} \\
\hline 2. & MWCNT & CPE & $20 \mathrm{nM}$ & Hair color and water samples & {$[46]$} \\
\hline 3. & MIP(PGA) & CPE & $8.91 \mu \mathrm{M}$ & Not analyzed & {$[47]$} \\
\hline
\end{tabular}

\subsection{Detection of Erythrosine (ER)}

Erythrosine (Figure 14) is a permitted color additive belonging to the xanthene class of dyes but is toxic, causing inhibition of various functions in the body such as various types of allergies, anemia, thyroid alteration, DNA damage, and cancer. The permissible limit for the usage of the dye given by the FDA is $1.4 \mathrm{mg}$ per person daily. It is a water-soluble organoiodine pink synthetic dye widely used as a food colorant, for printing inks, drugs, cocktails, tinned fruits, cosmetics, scotch egg, and snacks.

\section{Plodine}

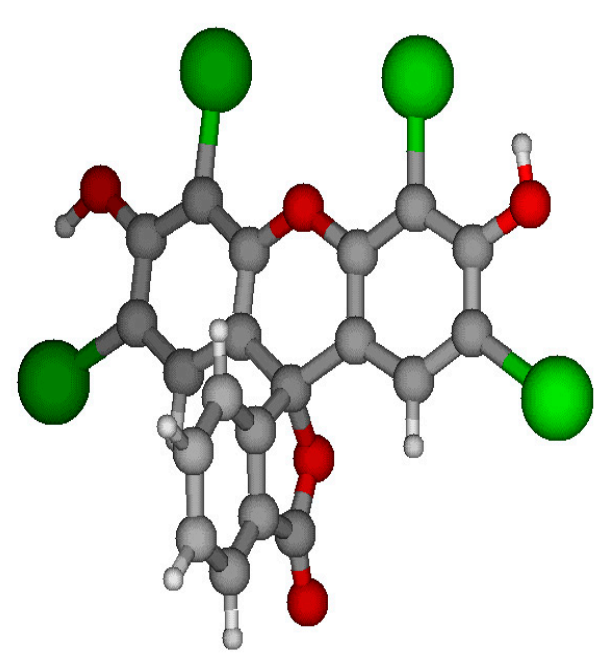

Figure 14. Ball and stick atomic model of Erythrosine.

In 2014, M. Golestanch et al. [48] used a MWCNT-modified CPE. This modified electrode possessed electro-catalytic activity as it enhanced peak currents (CV studies) and gave a detection limit of $5 \mathrm{nM}$. Real sample analysis in the food and cosmetic industry showed satisfactory results. D. S. Nayak et al. [49] detected ER at a glucose-modified CPE. The CV at the modified electrode showed two anodic peaks and enhancement of peak current as compared to bare CPE (displayed in Figure 15); the electron transfer process is an irreversible oxidation process, and the detection limit of the modified electrode is 
$21.6 \mathrm{nM}$. Real sample analyses were performed using dye-spiked human urine samples and results showed good recovery (91.6-98\%). M. Arvand et al. [50] also modified CPE using bimetallic Ni-Sn oxide hollow nanosphere (NS) in 2017. Electrochemical studies at this electrode showed a reversible peak with enhanced peak currents due to an increase in the number of active sites at the surface of the modified electrode. The interfering species gave an error of $\pm 10 \%$ in the determination of ER at this electrode with a detection limit of $2.1 \mathrm{nM}$. Real sample analysis results for gelatins, candies, and smarties at this electrode were confirmed by F-test (1.56-1.79) and $t$-test (2.02-1.78). Table 9 shows the detection limit of Erythrosine at the different modified carbon paste electrodes.

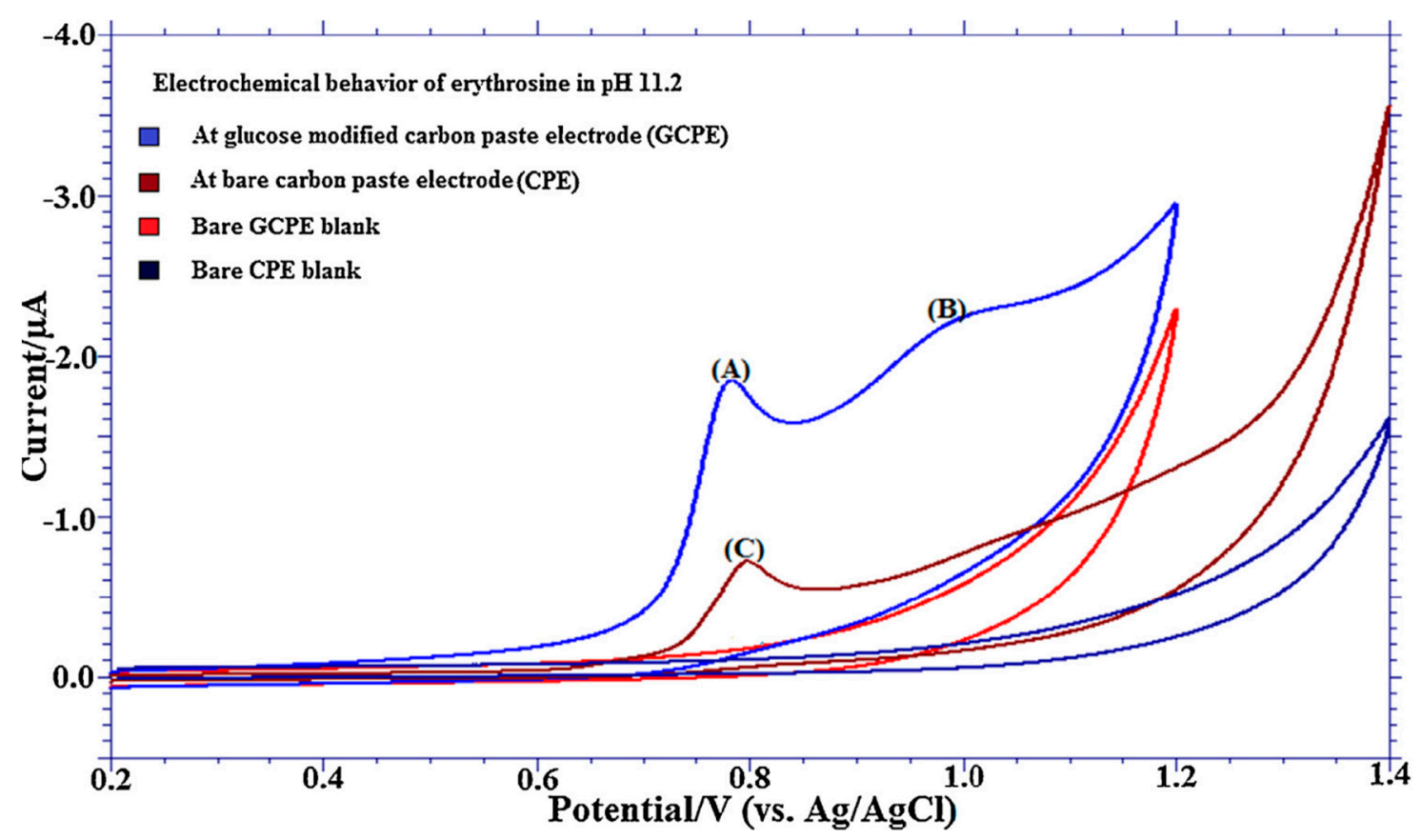

Figure 15. CV of ER at glucose modified carbon paste electrode and bare carbon paste electrode in $\mathrm{pH} 11.2$ phosphate buffer $(\mathrm{I}=0.2 \mathrm{M})$ at scan rate $=0.05 \mathrm{Vs}^{-1}$. Reprinted with the permission of Reference [49]. [License Number 5067500649853].

Table 9. Table showing Erythrosine detection using carbon paste electrodes with different modifiers along with their detection limits.

\begin{tabular}{cccccc}
\hline S.No. & Modifier & Working Electrode & Detection Limit & Real Sample Used & Reference \\
\hline 1. & MWCNT & CPE & $5 \mathrm{nM}$ & Drinks samples and cosmetic products \\
\hline 2. & Glucose & CPE & $21.6 \mathrm{nM}$ & Fruit juices and pharmaceutical \\
products & [49] \\
\hline 3. & Ni-Sn oxide NSs & CPE & $2.1 \mathrm{nM}$ & Powered gelatins, candies, and smarties & [50] \\
\hline
\end{tabular}

\subsection{Detection of Sudan}

Sudan dyes (Figure 16) are fat-soluble synthetic azo dyes having wide applicability ranging from industry to scientific research. Sudan dyes are aromatic synthetic chemical dyes having $(\mathrm{N}=\mathrm{N}-)$ azo groups. There are four kinds of Sudan, named Sudan I, II, III, and IV. These are used for coloring substances like oil, fats, waxes, hydrocarbon solvents, plastics, printing inks, textiles, leather, and wood. However, their use is banned in the food industry in various countries as they poses a threat to life due to their mutagenic, genotoxic, and carcinogenic properties. They are placed as category 3 toxins by the ICARC. 


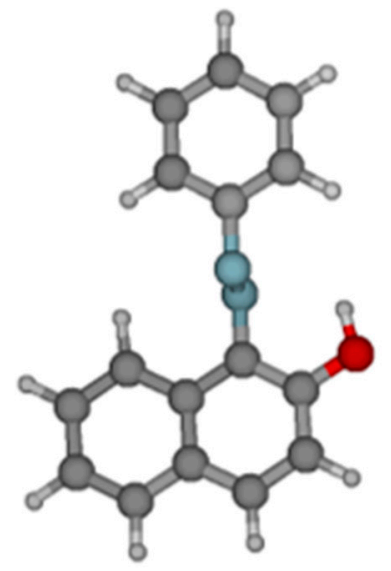

Sudan I.

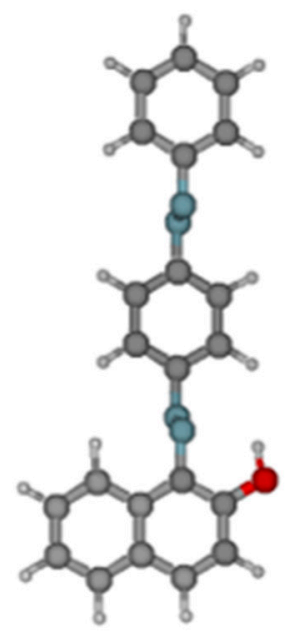

Sudan III.

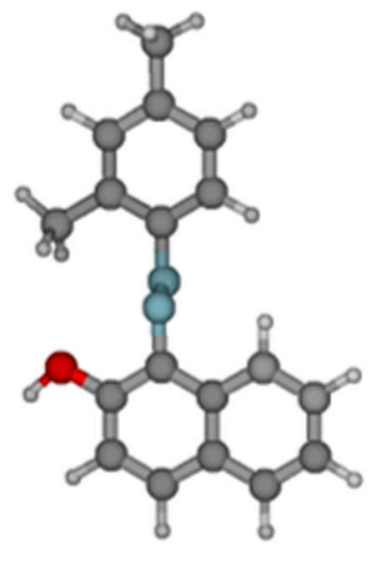

Sudan II.

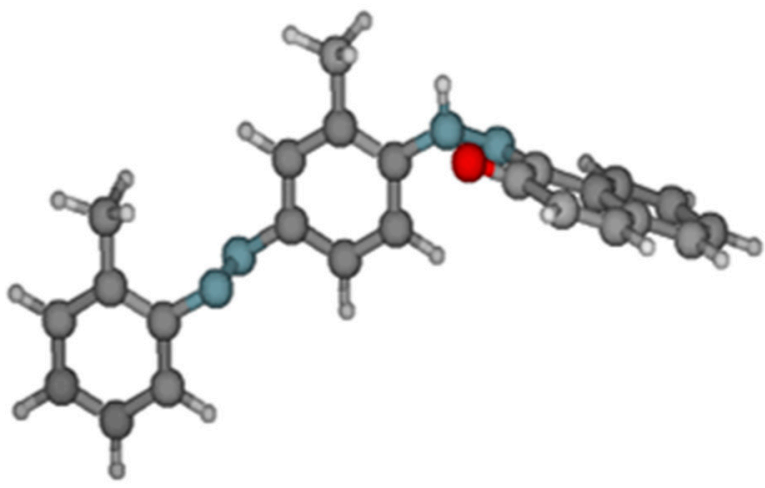

Sudan IV.

Figure 16. Ball and stick atomic model of Sudan.

In 2008, H. Lin et al. [51] detected Sudan I at a montmorillonite Ca modified CPE (Shown in Figure 17). The CV analysis showed a single well-defined, enhanced oxidation peak at the modified electrode. The modified electrode was also applied to examine the electrochemical behavior of other Sudan dyes (Sudan II, Sudan III, and Sudan IV) as shown in Figure 18. Each type of Sudan dye can be detected simultaneously at the Ca modified CPE. The Ca modified CPE showed good accuracy $(>88 \%)$ to detect Sudan dyes for real samples. In 2013, M. M. Elaysi et al. [52] detected Sudan I in food samples using Pt and carbon nanotube (CNT)-modified CPEs. Electrode performance was analyzed using CV. At the modified electrode interface CNT increased the oxidation peak current. Obtained $\mathrm{CV}$ results prove that $\mathrm{CNT}$ enhances the charge transfer kinetics between the modified electrode and Sudan I. The authors also studied the effect of various interferents like amino acids, organic biomolecules, cations $\left(\mathrm{Ca}^{2+}, \mathrm{Mg}^{2+}\right)$, and anions $\left(\mathrm{F}^{-}, \mathrm{ClO}_{4}{ }^{-}, \mathrm{SO}_{4}{ }^{2-}\right.$, etc. $)$ for the sensing of Sudan I. Later, the authors used the modified electrode to detect Sudan I in different food samples (chili sauce, chili powder, tomato sauce, and strawberry sauce). The CNT-modified electrode was able to detect the Sudan dyes in real samples with the detection limit $<0.003 \mu$ M. In 2014, Sudan I was also detected by J. B. Raoof et al. [53] using $\mathrm{ZnO}$ NPs and ionic-liquid-modified CPEs in the presence of vitamin $\mathrm{B}_{6}$. They found that the combination of ZnO NPs and ionic liquid will enhance charge transfer rate and sensitivity $(0.5446 \mu \mathrm{A} / \mu \mathrm{M})$, and prevents fouling of the CPE. In the same year, Sudan I was also detected simultaneously along with ascorbic acid using CPE modified from-NiO NPs 
and DEDED ((9,10-dihydro-9,10-ethanoanthracene-11,12-dicarboximido)-4-ethylbenzene1,2-diol).

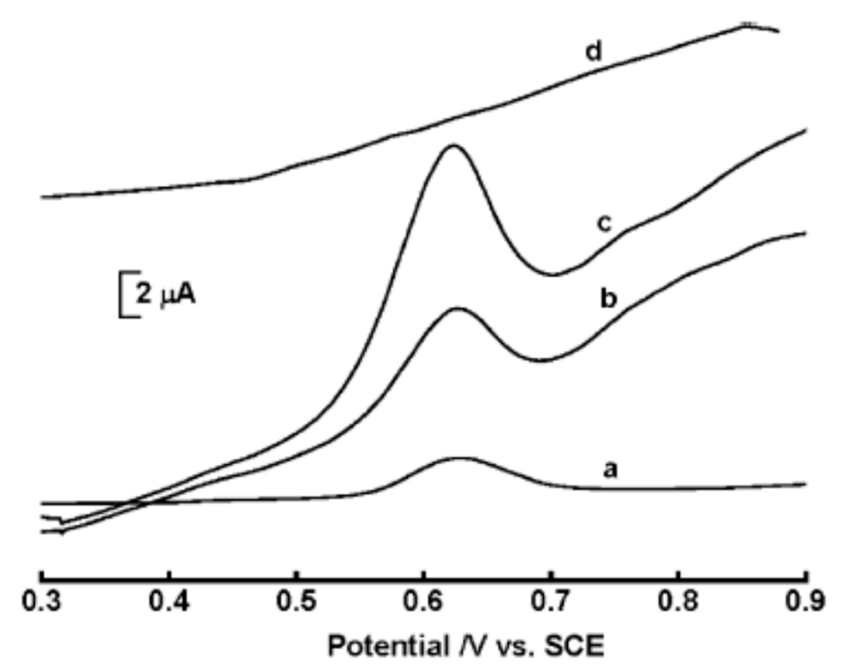

Figure 17. Square-wave voltammetric responses of Sudan I after 2 min accumulation. (a) $0.1 \mathrm{mg} \mathrm{L}^{-1}$ Sudan I at unmodified CPE; and (b-d) 0.1, 0.2, and $0 \mathrm{mg} \mathrm{L}^{-1}$ Sudan I at MMT-Ca modified CPE. Pulse height $=25 \mathrm{mV}$, pulse width $=10 \mathrm{~ms}$, scan rate $=100 \mathrm{mV} \mathrm{s}^{-1}$. Reprinted with the permission of Reference [51]. [License Number 5067500862861].

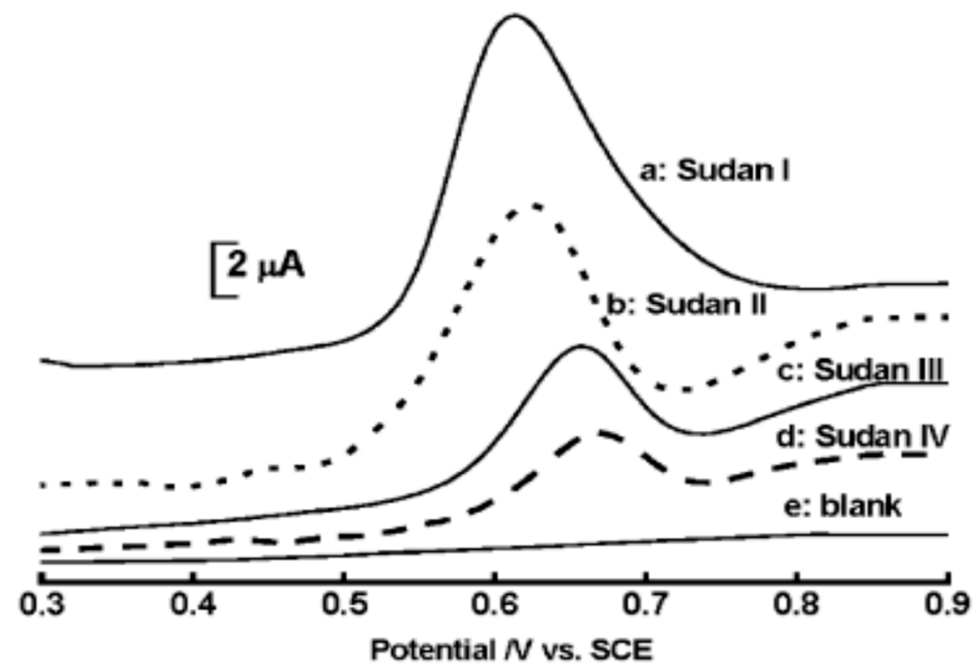

Figure 18. Square-wave voltammetric responses of $0.3 \mathrm{mg} \mathrm{L}^{-1}$ Sudan dyes at the MMT-Ca modified CPE after 2 min accumulation time. (a) Sudan I; (b) Sudan II; (c) Sudan III; (d) Sudan IV; and (e) blank voltammograms. Reprinted with the permission of Reference [51]. [License Number 5067500862861].

The modified CPE showed a detection limit of $0.2 \mu \mathrm{M}$ (K. Maleh et al. [54]). The authors proved that NiO NPs and DEDED act as electro-catalysts at the modified CPE interface. Heydari et al. [55] detected Sudan II at a CPE modified using ZnO NPs in 2019. They used CV to study the behavior of Sudan II at the ZnO NP-modified electrode and they found that NPs increase peak current 2.4 fold when compared to bare CPE. The increased peak currents at the modified electrodes are due to the increase in active surface area and charge transfer kinetics by NPs. NPs are also able to detect Sudan II in the presence of interference like different ions $\left(\mathrm{Ca}^{2+}, \mathrm{Mg}^{2+}, \mathrm{Zn}^{2+}\right)$, molecules (glucose, caffeine, phenol), and acids (ascorbic acid). Interferents had almost a $\pm 5 \%$ effect on peak currents. The detection limit of the ZnO NP-modified CPE was $0.0017 \mu \mathrm{M}$. In the same year M. Heydari et al. [56] used the ZnO NP-modified CPE for the determination of Sudan III. Like Sudan II, $\mathrm{ZnO}$ NP-modified electrode increases the peak currents of Sudan II when compared to bare 
CPE. The ZnO NP-modified CPE showed detection of $2.56 \mathrm{nM}$ for Sudan III. The authors also tested the proposed electrode to detect the Sudan III in chili sauce and ketchup, for which the results were good with a recovery limit $>95 \%$. Table 10 shows the detection limits of Sudan at the different modified carbon paste electrodes.

Table 10. Table showing Sudan detection using carbon paste electrodes with different modifiers along with their detection limits.

\begin{tabular}{|c|c|c|c|c|c|c|}
\hline S.No. & Dye & Modifier & $\begin{array}{l}\text { Working } \\
\text { Electrode }\end{array}$ & $\begin{array}{l}\text { Detection } \\
\text { Limit }\end{array}$ & Real Sample Used & Reference \\
\hline \multirow{4}{*}{1.} & \multirow{4}{*}{ Sudan I } & MMT-Ca & \multirow{4}{*}{$\mathrm{CPE}$} & $80.6 \mathrm{nM}$ & $\begin{array}{l}\text { Chili powder, chili sauce, and } \\
\text { ketchup }\end{array}$ & [51] \\
\hline & & $\mathrm{Pt} / \mathrm{CNT}$ & & $0.003 \mu \mathrm{M}$ & $\begin{array}{l}\text { Chili sauce, chili powder, tomato } \\
\text { sauce, and strawberry sauce }\end{array}$ & [52] \\
\hline & & $\mathrm{ZnO}$ NPs/IL & & $0.008 \mu \mathrm{M}$ & $\begin{array}{l}\text { Chili sauce, chili powder, tomato } \\
\text { sauce, and strawberry sauce }\end{array}$ & [53] \\
\hline & & NiO NPs/DEDED & & $0.2 \mu \mathrm{M}$ & $\begin{array}{l}\text { Spiked urine, chili sauce, and } \\
\text { tomato sauce }\end{array}$ & {$[54]$} \\
\hline 2. & Sudan II & $\mathrm{ZnO} N \mathrm{Ns}$ & CPE & $0.0017 \mu \mathrm{M}$ & Chili sauce and ketchup & [55] \\
\hline 3. & Sudan III & $\mathrm{ZnO} N P s$ & $\mathrm{CPE}$ & $2.56 \mathrm{~nm}$ & Chili sauce and ketchup & [56] \\
\hline
\end{tabular}

\section{Conclusions}

It is concluded that the various types of dyes used in the food, cosmetic, plastic, textile, and pharmaceutical industries for imparting colors represent a large group of organic compounds that have an undesirable effect on the environment. Some of the dyes can create difficulties and risks to humans if used and consumed within the undesired limit. Therefore, it has become necessary to perform a uniform search and generate new methods that are effective and economically manageable for the determination of the dyes. Voltammetric methods are among these and are highly economical to both environment and humans, and carbon paste electrodes are widely employed in these methods. A carbon paste electrode is a heterogeneous system in which graphite powder is mixed with a pasting liquid (paraffin wax/silicone oil). They can be modified easily with various modifiers (e.g., MIP, organic molecules, inorganic molecules, CNTs, IL, etc.), so are equipped with great advantages such as low production cost, precise results, ready to use, and good stability. Due to this, they have a wide scope of applications in the detection of dyes even at very low concentration levels. Modifying the electrode also helps in improving specificity and increasing electroactive sites for interaction of the analyte for easy detection. The current review can form a basis for extensive research for using various other biomolecules for modifying CPEs apart from the above-mentioned, which can further improve the detection limits with improved accuracy and precision for a specific dye. These carbonbased modified sensors are not only helpful in dye detection but are being employed in discovering various other pollutants of wastewater such as byproducts, metal ions, organic molecules, etc.

Author Contributions: Writing—original draft preparation, validation, and formal analysis: I.S.; formal analysis, validation, and resources: P.K.; formal analysis: S.S.; methodology, conceptualization, and editing G.K.J. All authors have read and agreed to the published version of the manuscript.

Funding: This research received no external funding.

Institutional Review Board Statement: Not applicable.

Informed Consent Statement: Not applicable.

Data Availability Statement: Not applicable. 
Acknowledgments: The authors dedicate the current article to B. E. Kumara Swamy, Chairman, Department of Industrial Chemistry, Kuvempu University, Karnataka, India.

Conflicts of Interest: The authors declare no conflict of interest.

\section{References}

1. Forgacs, E.; Cserháti, T.; Oros, G. Removal of synthetic dyes from wastewaters: A review. Environ. Inter. 2004, 30, 953-971. [CrossRef]

2. Ali, H. Biodegradation of Synthetic Dyes-A Review. Water Air Soil Pollut. 2010, 213, 251-273. [CrossRef]

3. Rawat, D.; Sharma, R.S.; Karmakar, S.; Arora, L.S.; Mishra, V. Ecotoxic potential of a presumably non-toxic azo dye. Ecotoxicol. Environ. Saf. 2018, 148, 528-537. [CrossRef] [PubMed]

4. Moattari, R.M.; Mohammadi, T. Hybrid Adsorbents for Dye Removal from Wastewater. In Green Adsorbents to Remove Metals; Springer: New York, NY, USA, 2021; Volume 49, pp. 405-451.

5. Sana, K.; Mohammad, A.; Abdul, M. Mutagenicity and genotoxicity evaluation of textile industry wastewater using bacterial and plant bioassays. Toxicol. Rep. 2019, 6, 193-201.

6. Mondal, S. Methods of Dye Removal from Dye House Effluent-An Overview. Environ. Eng. Sci. 2008, 25, 383-396. [CrossRef]

7. Goswami, L.; Chandrashekhar, M. India: Indian Food Safety Laws-Implications for Foreign Operators Importing Food Into India. Eur. Food Feed Law Rev. 2012, 7, 154-156.

8. Kobylewski, S.; Jacobson, M.F. Toxicology of food dyes. Int. J. Occup. Environ. Health 2012, 18, 1077-3525. [CrossRef]

9. Benkhaya, S.; Mrabet, S.; Harfi, A.E. A review on classifications, recent synthesis and applications of textile dyes. Inorg. Chem. Commun. 2020, 115, 107891. [CrossRef]

10. Yaseen, D.A.; Scholz, M. Textile dye wastewater characteristics and constituents of synthetic effluents: A critical review. Int. J. Environ. Sci. Technol. 2019, 16, 1193-1226. [CrossRef]

11. Rawat, D.; Mishra, V.; Sharma, R.S. Detoxification of azo dyes in the context of environmental processes. Chemosphere 2016, 155, 591-605. [CrossRef]

12. Šuleková, M.; Smrčová, M.; Hudák, A.; Hezelova, M.; Fedorová, M. Organic colouring agents in the pharmaceutical industry. Folia Vet. 2017, 61, 32-46. [CrossRef]

13. Saini, R.D. Textile organic dyes: Polluting effects and elimination methods from textile waste water. Int. J. Chem. Eng. Res. 2017, 9, 121-136.

14. Guerra, E.; Llompart, M.; Garcia-Jares, C. Analysis of Dyes in Cosmetics: Challenges and Recent Developments. Cosmetics 2018, 5, 47. [CrossRef]

15. Zima, J.; Barek, J.; Moreira, J.C.; Mejstř́k, V.; Fogg, A.G. Electrochemical determination of trace amounts of environmentally important dyes. Fresenius' J. Anal. Chem. 2001, 369, 567-570. [CrossRef] [PubMed]

16. Jayaprakash, G.K.; Swamy, B.E.K.; Ramirez, H.N.G.; Ekanthappa, M.T.; Flores-Moreno, R. Quantum chemical and electrochemical studies of lysine modified carbon paste electrode surfaces for sensing dopamine. New J. Chem. 2018, 42, 4501-4506. [CrossRef]

17. Jayaprakash, G.K.; Swamy, B.E.K.; Casillas, N.; Flores-Moreno, R. Analytical Fukui and cyclic voltammetric studies on ferrocene modified carbon electrodes and effect of Triton X-100 by immobilization method. Electrochim. Acta 2017, 258, 1025-1034. [CrossRef]

18. Jayaprakash, G.K.; Swamy, B.E.K.; Chandrashekar, B.N.; Flores-Moreno, R. Theoretical and cyclic voltammetric studies on electrocatalysis of benzethonium chloride at carbon paste electrode for detection of dopamine in presence of ascorbic acid. J. Mol. Liq. 2017, 240, 395-401. [CrossRef]

19. Marken, F.; Neudeck, A.; Bond, A.M. Cyclic Voltammetry. In Electroanalytical Methods; Scholz, F., Ed.; Springer: Berlin/Heidelberg, Germany, 2005. [CrossRef]

20. Chen, X.; Wu, K.; Sun, Y.; Song, X. Highly sensitive electrochemical sensor for sunset yellow based on the enhancement effect of alumina microfibers. Sens. Actuators B Chem. 2013, 185, 582-586. [CrossRef]

21. Songyang, Y.; Yang, X.; Xie, S.; Hao, H.; Song, J. Highly-sensitive and rapid determination of sunset yellow using functionalized montmorillonite-modified electrode. Food Chem. 2014, 173, 640-644. [CrossRef]

22. Sun, D.; Xu, C.; Long, J.; Ge, T. Determination of Sunset Yellow using a carbon paste electrode modified with a nanostructured resorcinol-formaldehyde resin. Microchim. Acta 2015, 182, 2601-2606. [CrossRef]

23. Wang, Z.; Shan, Y.; Xu, L.; Wu, G. Determination of the azo dye, sunset yellow, using carbon paste electrode modified with molecularly imprinted polymer. Indian J. Chem. Sect. A 2016, 55, 1458-1464.

24. Ya, Y.; Jiang, C.; Li, T.; Liao, J.; Fan, Y.; Wei, Y.; Yan, F.; Xie, L. A Zinc Oxide Nanoflower-Based Electrochemical Sensor for Trace Detection of Sunset Yellow. Sensors 2017, 17, 545. [CrossRef] [PubMed]

25. Ghoreishi, S.M.; Behpour, M.; Golestaneh, M. Selective Voltammetric Determination of Tartrazine in the Presence of Red 10B by Nanogold-modified Carbon Paste Electrode. J. Chin. Chem. Soc. 2013, 60, 120-126. [CrossRef]

26. Karim-Nezhad, G.; Khorablou, Z.; Zamani, M.; Dorraji, P.S.; Alamgholiloo, M. Voltammetric sensor for tartrazine determination in soft drinks using poly (p-aminobenzenesulfonic acid)/zinc oxide nanoparticles in carbon paste electrode. J. Food Drug Anal. 2016, 25, 293-301. [CrossRef]

27. Chenthattil, R.; Manjunatha, J.G.; Tigari, G.; Nagarajappa, N.H. Fabrication of the Tartrazine Voltammetric Sensor based on Surfactant Modified Carbon Paste Electrode. Open Access J. Chem. 2018, 2, 21-26. 
28. Manjunatha, J.G. A novel voltammetric method for the enhanced detection of the food additive tartrazine using an electrochemical sensor. Heliyon 2018, 4, 1-14. [CrossRef]

29. Chenthattil, R.; Manjunatha, J.G. Development of Sodium Dodecyl Sulfate Based Electrochemical Sensor for Tartrazine Determination. Portugaliae Electrochim. Acta 2021, 39, 59-70.

30. Ghoreishi, S.M.; Behpour, M.; Golestaneh, M. Simultaneous determination of Sunset yellow and Tartrazine in soft drinks using gold nanoparticles carbon paste electrode. Food Chem. 2012, 132, 637-641. [CrossRef]

31. Marquez-Mariño, K.; Penagos-Llanos, J.; García-Beltrán, O.; Nagles, E.; Hurtado, J.J. Development of a Novel Electrochemical Sensor Based on a Carbon Paste Electrode Decorated with $\mathrm{Nd}_{2} \mathrm{O}_{3}$ for the Simultaneous Detection of Tartrazine and Sunset Yellow. Electroanalysis 2018, 30, 2760-2767. [CrossRef]

32. Penagos-Llanos, J.; García-Beltrán, O.; Calderón, J.A.; Hurtado-Murillo, J.J.; Nagles, E.; Hurtado, J.J. Simultaneous determination of tartrazine, sunset yellow and allura red in foods using a new cobalt-decorated carbon paste electrode. J. Electroanal. Chem. 2019, 852, 113517. [CrossRef]

33. Pandurangachar, M.; Niranjana, E.; Swamy, B.E.K.; Sherigara, B.S.; Pai, K.V. Electrochemical studies of amaranth at surfactant modified carbon paste electrode: A cyclic voltammetry. Int. J. Electrochem. Sci. 2008, 3, 588-596.

34. Wang, M.L.; Zhang, J.; Ding, N.N.; Zhu, X.L.; Chen, Z.D. Electrochemical detection of amaranth in food based on the expanded graphite paste electrode. J. AOAC Int. 2013, 96, 625-629. [CrossRef]

35. Sheikhshoaee, M.; Karimi-maleh, H.; Sheikhshoaie, I.; Ranjbar, M. Voltammetric amplified sensor employing RuO2 nano-road and room temperature ionic liquid for amaranth analysis in food samples. J. Mol. Liq. 2017, 229, 489-494. [CrossRef]

36. Bijad, M.; Karimi-Maleh, H.; Farsi, M.; Shahid, S.A. Simultaneous Determination of Amaranth and Nitrite in Foodstuffs via Electrochemical Sensor Based on Carbon Paste Electrode Modified with CuO/SWCNTs and Room Temperature Ionic Liquid. Food Anal. Methods 2017, 10, 3773-3780. [CrossRef]

37. Akbari, S. A new voltammetric sensor according to graphene quantum dots/ionic liquid modified carbon paste electrode for amaranth sensitive determination. Int. J. Environ. Anal. Chem. 2020, 1-15. [CrossRef]

38. Zhang, J.; Zhang, S.; Wang, X.; Wang, W.; Chen, Z. Simultaneous determination of Ponceau-4R and Allura Red in soft drinks based on the ionic liquid modified expanded graphite paste electrode. Int. J. Environ. Anal. Chem. 2015, 95, 581-591. [CrossRef]

39. Penagos-Llanos, J.; García, O.; Calderón, J.; Edgar, N.; Hurtado, J. Carbon Paste Composite with Co3O4 as a New Electrochemical Sensor for the Detection of Allura Red by Reduction. Electroanalysis 2019, 31, 695-703. [CrossRef]

40. Pliuta, K.; Chebotarev, A.; Pliuta, A.; Snigur, D. Voltammetric Determination of Allura Red AC onto Carbone-Paste Electrode Modified by Silica with Embedded Cetylpyridinium Chloride. Electroanalysis 2020, 33, 987-992. [CrossRef]

41. Rozhin, D.; Shabani-Nooshabadi, M. $\mathrm{NiFe}_{2} \mathrm{O}_{4}-\mathrm{rGO} /$ ionic liquid modified carbon paste electrode: An amplified electrochemical sensitive sensor for determination of Sunset Yellow in the presence of Tartrazine and Allura Red. Food Chem. 2021, 339, 127841/1-9.

42. Bijad, M.; Karimi-Maleh, H.; Farsi, M.; Shahidi, S.A. An electrochemical-amplified-platform based on the nanostructure voltammetric sensor for the determination of carmoisine in the presence of tartrazine in dried fruit and soft drink samples. J. Food Meas. Charact. 2018, 12, 634-640. [CrossRef]

43. Nezhad, H.M.; Seyed-Ahmad, S.; Bijad, M. Fabrication of a Nanostructure Voltammetric Sensor for Carmoisine Analysis as a Food Dye Additive. Anal. Bioanal. Electrochem. 2018, 10, 220-229.

44. Chebotarev, A.; Pluta, K.; Snigur, D. Determination of Carmoisine onto Carbon-Paste Electrode Modified by Silica Impregnated with Cetylpyridinium Chloride. Chem. Select. 2020, 5, 3688-3693. [CrossRef]

45. Noviandri, I.; Raminas, A. The Effect of Tartrazine in Voltammetric Determination of Rhodamine B with Molecularly Imprinted Poly (3-Aminophenol) Modified Carbon Electrode. Funct. Mater. Technol. 2019, 811, 107-112.

46. Golestaneh, M.; Ghoreishi, S.M. Sensitive Determination of Rhodamine B in Real Samples at the Surface of a Multi-walled Carbon Nanotubes Paste Electrode. Anal. Bioanal. Electrochem. 2020, 12, 81-92.

47. Setiyanto, H.; Ferizal, F.; Rahayu, V.S.R.S.; Zulfikar, M.A. Carbon paste electrode modified Poly-Glutamic Acid (PGA) with molecularly imprinted for detection of Rhodamine B. IOP Conf. Ser. Mater. Sci. Eng. 2021, 1088, 012113. [CrossRef]

48. Golestaneh, M.; Ghoreishi, S.M. Electrochemical determination of erythrosine in real sample using a carbon paste electrode modified with multi-walled carbon nanotube. In Proceedings of the Iranian Biennial Electrochemistry Seminar, Guilan, Iran, 9-11 September 2014.

49. Nayak, D.S.; Shetti, N.P. A novel sensor for a food dye erythrosine at glucose modified electrode. Sens. Actuators B Chem. 2016, 230, 140-148. [CrossRef]

50. Arvand, M.; Pourhabib, A.; Asadi, M. Template-based synthesis of uniform bimetallic nickel-tin oxide hollow nanospheres as a new sensing platform for detection of erythrosine in food products. Sens. Actuators B Chem. 2018, 255, 1716-1725. [CrossRef]

51. Lin, H.; Li, G.; Wu, K. Electrochemical determination of Sudan I using montmorillonite calcium modified carbon paste electrode. Food Chem. 2007, 107, 531-536. [CrossRef]

52. Elyasi, M.; Khalilzadeh, M.A.; Karimi-Maleh, H. High sensitive voltammetric sensor based on Pt/CNTs nanocomposite modified ionic liquid carbon paste electrode for determination of Sudan I in food samples. Food Chem. 2013, 141, 4311-4317. [CrossRef]

53. Raoof, J.B.; Teymoori, N.; Khalilzadeh, M. ZnO Nanoparticle Ionic Liquids Carbon Paste Electrode as a Voltammetric Sensor for Determination of Sudan I in the Presence of Vitamin B6 in Food Samples. Food Anal. Methods 2014, 8, 885-892. [CrossRef] 
54. Karimi-Maleh, H.; Moazampour, M.; Yoosefian, M.; Sanati, A.L.; Tahernejad-Javazmi, F.; Mahani, M. An Electrochemical Nanosensor for Simultaneous Voltammetric Determination of Ascorbic Acid and Sudan I in Food Samples. Food Anal. Methods 2014, 7, 2169-2176. [CrossRef]

55. Heydari, M.; Ghoreishi, S.M.; Khoobi, A. Novel electrochemical procedure for sensitive determination of Sudan II based on nanostructured modified electrode and multivariate optimization. Measurement 2019, 142, 105-112. [CrossRef]

56. Heydari, M.; Ghoreishi, S.M.; Khoobi, A. Response surface modeling of electrochemical data for sensitive determination of Sudan III in food products at the surface of a nanocomposite modified electrode. Food Anal. Methods 2019, 12, 1781-1790. [CrossRef] 